\title{
Resolution of Radiation-Induced Necrosis in Arteriovenous Malformation with Bevacizumab: A Case Report and Review of Current Literature
}

\author{
Forrest Kwong a Daphne B. Scarpellib Ramon F. Barajas $^{c, d}$, e \\ Debra Monaco $^{b}$ James A. Tanyi ${ }^{b}$ Shearwood McClelland ${ }^{f}$ \\ Jerry J. Jaboin ${ }^{b}$ \\ aschool of Medicine, Oregon Health \& Science University, Portland, OR, USA; ${ }^{b}$ Department \\ of Radiation Medicine, Oregon Health \& Science University, Portland, OR, USA; \\ 'Department of Diagnostic Radiology, Oregon Health \& Science University, Portland, OR, \\ USA; ${ }^{d}$ Advanced Imaging Research Center, Oregon Health \& Science University, Portland,

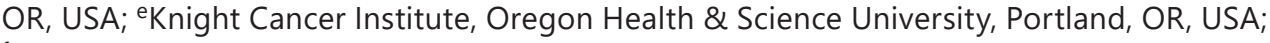 \\ fDepartment of Radiation Oncology, Indiana University, Indianapolis, IN, USA
}

Keywords

Arteriovenous malformation · Stereotactic radiosurgery · Bevacizumab · Radiation-induced necrosis

\begin{abstract}
Stereotactic radiosurgery (SRS) is a proven treatment modality for inoperable arteriovenous malformations (AVMs). However, the rate of radiation-induced necrosis (RIN) is as high as $10 \%$. A 6-year-old female patient presented with severe headache, emesis, and syncope, and workup revealed a Spetzler-Martin grade 4 AVM with intraventricular hemorrhage and hydrocephalus. The patient underwent a right frontal ventriculostomy followed by a linear acceleratorbased SRS of 16.9 Gy. At 19 years, she developed progressive neurological symptoms. Diagnostic magnetic resonance imaging (MRI) revealed a recurrent parietal AVM nidus. We delivered the linear accelerator-based SRS of 18.5 Gy to the AVM nidus. Within 9 months, she experienced episodic headaches and left-sided weakness and spasticity; symptoms were initially managed with dexamethasone. Follow-up MRI was notable for edema and nondetectable blood flow, consistent with RIN and AVM obliteration. The second course of steroids did not provide the symptom control. Persistent RIN was noted on MRI, and she had stigmata of steroid toxicity (centripetal obesity, depression, and sleep disorder). Two infusions of bevacizumab $(5 \mathrm{mg} / \mathrm{kg}$ ) were administered concurrently with a tapering dose of dexamethasone. The patient noted a near immediate improvement in her headaches, and 2 months following the second bevacizumab infusion, she reported a near-complete resolution of her symptoms
\end{abstract}


and displayed improved ambulation. The development of RIN remains a noteworthy concern post-SRS of AVMs. While steroids aid with initial management of RIN, for persistent and recurrent symptoms, bevacizumab infusions serve as a viable treatment course, with the added benefit of reducing the likelihood of adverse effects resulting from prolonged steroid therapy.

(C) 2021 The Author(s).

Published by S. Karger AG, Basel

\section{Introduction}

Stereotactic radiosurgery (SRS) is a proven treatment modality for inoperable high-risk arteriovenous malformations (AVM) [1]. However, SRS administration has been associated with late toxicities, such as radiation-induced necrosis (RIN), which can present symptomatically in $2-14 \%$ of patients and neuroradiologically in $\leq 46 \%$ [2]. Steroid therapy is the primary mean for managing RIN, while the efficacy of bevacizumab, an angiogenesis inhibitor, is currently under investigation. This case report highlights the occurrence of RIN post-SRS administration in AVM and the resolution of symptoms using bevacizumab.

\section{Case Report}

A 6-year-old patient presented with a history of headaches and acute presentations of severe headache, emesis, and syncope. Computed tomography (CT) showed intraventricular hemorrhage with hydrocephalus. Magnetic resonance imaging (MRI) revealed a large right parietal AVM. Cerebral angiogram confirmed a parietal parasagittal angiomatous-type AVM, which due to its nidus size $(>5 \mathrm{~cm})$, eloquent cortex involvement (sensorimotor), and deep venous drainage (draining into the superior sagittal sinus) met the criteria for a SpetzlerMartin grade 4 AVM [3].

Based on the Spetzler-Martin grade, this AVM was deemed a suboptimal embolization and surgery candidate; a right frontal ventriculostomy was placed, resulting in a resolution of hydrocephalus. The ventriculostomy was removed, and the patient was discharged without residual deficits. Due to a lack of medical insurance, she received a linear accelerator-based SRS of 16.9 Gy approximately a year later. Three months post-SRS, she developed left-sided weakness and episodic partial motor seizures, initiating dexamethasone $1 \mathrm{mg} /$ day and Keppra management. MRI revealed edema in the right cerebral hemisphere, leading to prolonged dexamethasone management and slow stabilization of her left-sided motor function with physical therapy. Five years post-SRS, she experienced 2 months of worsening occipital area headaches, 2-3 times a day and increased left-sided weakness with left upper extremity contracture. MRI indicated enhancing vessels into the previous SRS site with stable encephalomalacia and gliosis of the right posterior medial frontal and anterior medial parietal lobes. She underwent renewed physical and occupational therapy. At 19 years, her neuroangiogram indicated a $1.6-\mathrm{cm}$ parietal AVM with 2 residual pericallosal and interhemispheric draining veins consistent with a Spetzler-Martin grade 3 lesion, which was treated with the linear accelerator-based SRS. The nidus was delineated with 18.5 Gy prescribed to at least $95 \%$ of the target volume in 1 fraction (shown in Fig. 1a). All dose constraints were met as illustrated in Figure 1b [1].

Over the 9 months following her second SRS, she developed episodic headaches, and leftsided spasticity and weakness; symptoms were managed on intermittent treatment with dexamethasone. While initially, symptoms were controlled on dexamethasone, after tapering

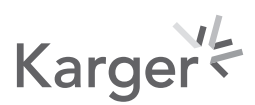




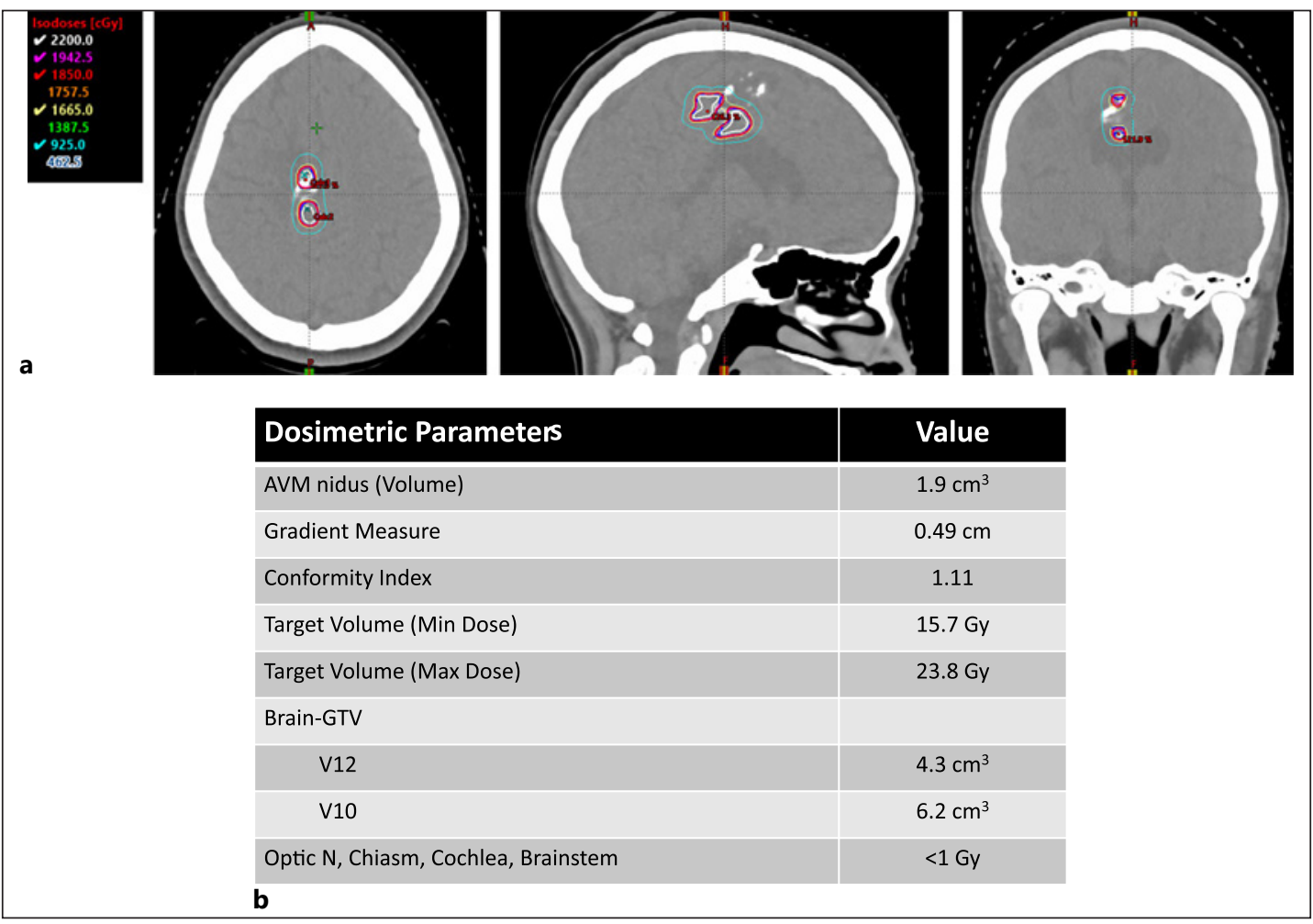

Fig. 1. Linear accelerator-based SRS was performed using a high-resolution MLC system (HD-MLC; $2.5 \mathrm{~mm}$ at isocenter; Novalis Tx, Brainlab/Varian Medical Systems, Palo Alto, CA, USA). Volumetric On-Board Imager (OBI, Varian Medical System, Palo Alto, CA, USA) and ExacTrac X-ray 6 degree-of-freedom system (ExacTrac, BrainLab, Munich, Germany) were used for patient positioning, positional verification, and the intrafraction motion assessment. A custom-fit thermoplastic mask (Orfit, OrfitIndustries, Wijnegem, Belgium) was used for cranial immobilization. MRI data plus a reference planning CT were imported into Eclipse v.15.1 (Varian Medical Systems, Inc., Palo Alto, CA, USA) for target delineation and dose computation with Acuros, respectively. Four volumetric modulated arcs were used to deliver a prescription (Rx) dose 18.5 Gy to at least $95 \%$ of the irregularly shaped AVM nidus. a Axial/sagittal/coronal views, respectively, through the isocenter of the AVM nidus with corresponding IDL on the legend. b Key dosimetric data and planning constraints. AVM, arteriovenous malformations; SRS, stereotactic radiosurgery; MRI, magnetic resonance imaging; CT, computed tomography; IDL, isodose lines.

off of dexamethasone, her spasticity, headaches, and other general symptoms would return each time with varying latency. She suffered depression and anxiety attacks related to her symptoms, impairing her quality of life and contributing to delays in her education.

Nine months post-SRS, MRI demonstrated edema consistent with RIN and AVM obliteration (as shown in Fig. 2). Steroids were recommended, but considering that her swelling likely peaked, the clinical team focused on the symptom management as she had the stigmata of steroid toxicity (facial/neck plethora, increased centripetal weight, fatigue, and disrupted sleep). However, at 12 months post-SRS, she demonstrated no improvement and her MRI showed persistent RIN. Given her history of dexamethasone tapers, steroid toxicity, and the negative impact on her quality of life, the patient was evaluated for bevacizumab. Two bevacizumab infusions ( $5 \mathrm{mg} / \mathrm{kg}$ ) were started 14 months post-SRS, 2 weeks apart. Bevacizumab was administered with $2 \mathrm{mg}$ dexamethasone ongoing at every other day since her prior emergency room visit for RIN-related symptoms. Her symptoms improved within the first 24 hours. Five weeks from the last bevacizumab infusion, the extent of both the enhancement and associated surrounding T2 FLAIR hyperintensity mildly decreased without evidence of 


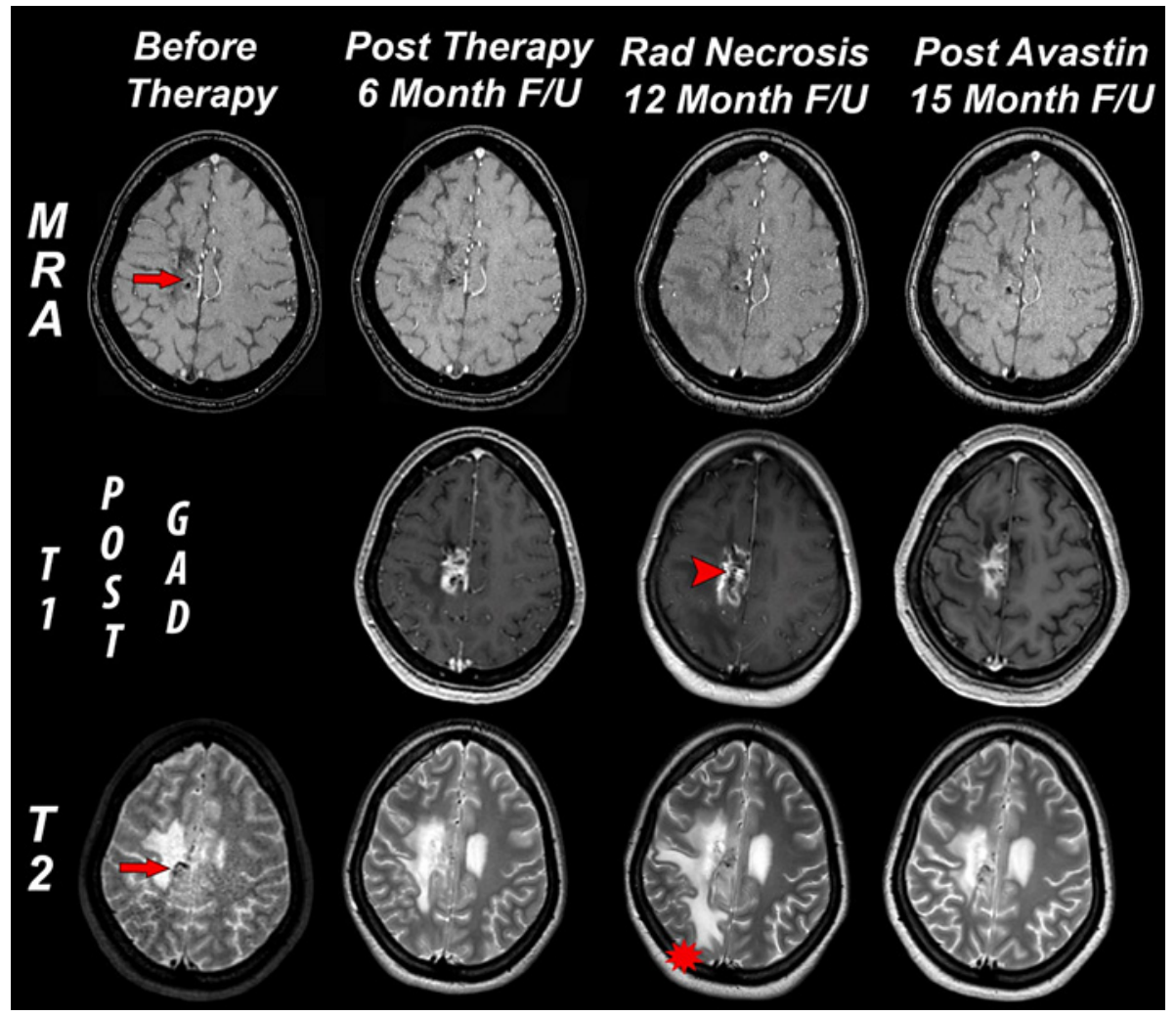

Fig. 2. AVM Radiation Necrosis. Pre-therapeutic MRA (top left column) demonstrates a vascular nidus (red arrow) with flow-related enhancement surrounded by T2 signal hyperintensity (bottom left column) consistent with vasogenic edema. Follow-up MRA 6 months after the radiation therapy demonstrates resolution of the vascular nidus (top middle left column) with contrast enhancement involving the radiation field (middle left column). Upon 12 months follow-up imaging, the contrast enhancing focus (middle right column, arrow head) was noted to enlarge and develop central necrosis concurrent with marked increased vasogenic edema on T2-weighted imaging (bottom middle right column, star) without evidence of recurrent vascular nidus that was felt to be consistent with therapy-induced radiation necrosis. Serial follow-up MRI following bevacizumab therapy demonstrates a diminished central necrosis and vasogenic edema. AVM, arteriovenous malformations; MRA, magnetic resonance angiography.

acute hemorrhage or intracranial mass. The patient noted subjective improvements in mood, sleep, light sensitivity, and ability to rise from a seated position without orthostatic hypotension. Her headaches and weakness nearly resolved 2 months after the final bevacizumab infusion, and the patient reported walking and running. One adverse symptom our patient continues to notice is episodes of hypertonicity, which is treated with dantrolene. This, however, is preferred to her years of flaccidity in this extremity, and she continues to be happy with her current outcomes. She has returned to school and has not had a bout of major depression since infusion.

\section{Discussion}

High-radiation dose has been well documented to increase AVM obliteration rates but must be cautiously selected to minimize the risk of hemorrhage and adverse radiation effects, such as RIN [1,4]. In a single-institution study of 1,400 AVM patients who proceeded with gamma knife surgery, Yen et al. [5] calculated an annual hemorrhage rate 
after an AVM diagnosis of $6.6 \%$. This rate was observed to decline to $2.5 \%$ post-radiosurgery and $0 \%$ with confirmed angiographic obliteration. Potts et al. [6] reported that a pediatric cohort treated with $\geq 18$ Gy had a significantly higher rate of 3-year angiographic obliteration (52\%, $p=0.015)$ and lower occurrence of post-SRS hemorrhage $(3 \%, p=$ 0.0003 ) than the patients treated with $<18$ Gy of $16 \%$. Similarly, Miyawaki et al. [7] observed obliteration rates of $60 \%$ and $9 \%$, respectively, in patients who received 18 Gy and $\leq 14 \mathrm{~Gy}$. Increased risk of post-SRS hemorrhage was also associated with decreased minimum dose $(p=0.05)$ and treatment volume $(p=0.001)$. However, RIN requiring resection was noted to occur in $22 \%$ of the patients treated with $\geq 16$ Gy for AVM of $>14$ $\mathrm{cm}^{3}$ [7]. Additional studies have identified treatment dose-volume to significantly increase the risk for post-SRS complications [1, 4]. Pollock et al. [4] highlighted the potential benefits of volume-staged SRS, especially in cases with large AVM $\left(>14 \mathrm{~cm}^{3}\right)$. Volume-staged SRS allows for high-radiation dose delivery to the entire AVM lesion over several sessions while minimizing radiation exposure to adjacent anatomical structures. In our institution, we separated the AVM volume to $\leq 10 \mathrm{~cm}^{3}$ per treatment session to increase the overall obliteration rates and reduce risks of posttreatment toxicity. This approach has been associated with $28-68 \%$ complete or near-complete obliteration rates in AVM treated with $\geq 17$ Gy and decreased risk for permanent adverse radiation effects at $6.6 \%$ [4].

RIN affects $10 \%$ of the patients who undergo SRS for AVM [1]. Symptomatic RIN depends on the anatomic location of AVM and may include headache, paralysis, and ataxia. While steroid treatment is the first-line therapy, steroid-refractory RIN remains a challenge to treat and requires further research. A randomized double-blind clinical trial by Levin et al. [8] aimed to test the efficacy of bevacizumab in patients with RIN who underwent SRS for the head and neck cancer, meningioma, or low-mid grade glioma. This study showed reduction of necrosis among all the patients within the treatment arm and no reduction in the control group. Furthermore, all the patients treated with bevacizumab experienced improved neurological symptoms contrary to the outcomes in the control group. While the previous clinical trial did not examine RIN post-SRS for AVM, the results suggest that bevacizumab could be a viable treatment for patients with steroidresistant RIN. Drawbacks to this study include mixed results when comparing bevacizumab and the control groups with cognitive improvement tests. Furthermore, of the 11 patients treated with bevacizumab, 3 developed serious adverse effects (pneumonia, superior sagittal sinus thrombosis, and DVT with related PE). Patients treated with bevacizumab should be monitored for potential toxicities including but not limited to hypertension, proteinuria, gastrointestinal perforation, and hemorrhage. Hypertension and proteinuria can typically be managed with traditional approaches. Even minor gastrointestinal symptoms should be examined suspiciously for a perforation [9]. Bevacizumab is a risk factor for hemorrhage which is especially concerning in a patient with a history of brain AVM, however, in oncological settings, studies have shown that the CNS-specific hemorrhages are not at increased risk $[10,11]$.

Previous examples of the anti-vascular endothelial growth factor medication, bevacizumab, have shown to variably reduce RIN (as shown in Table 1). Williams et al. [12] was the first case report of using bevacizumab for steroid-refractory RIN in a patient who underwent SRS for AVM. Williams et al. [12] reported improvement in symptoms - including reduction of headaches and increased strength - and a reduction in T2 FLAIR. Preuss et al. [13] supplied examples of using bevacizumab in pediatric patients with mixed results. Both the patients experienced marked reduction in T2 FLAIR but with only initial symptom improvement that proved marginal long-term. Dashti et al. [14] gave bevacizumab following hyperosmotic blood-brain-barrier disruption to minimize the dose of bevacizumab given.

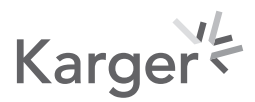


Table 1. Current literature on RIN treated with bevacizumab

\begin{tabular}{|c|c|c|c|c|c|}
\hline Study & $\begin{array}{l}\text { Patient } \\
\text { characteristics }\end{array}$ & Dose $\mathrm{X}$ frequency & AVM status & Symptom improvement & $\begin{array}{l}\text { Radiological } \\
\text { improvement }\end{array}$ \\
\hline $\begin{array}{l}\text { Williams } \\
\text { et al. [12] }\end{array}$ & 20 yr female & $\begin{array}{l}2.5 \mathrm{mg} / \mathrm{kg} \\
\text { initial dose., } \\
\text { then } 7.5 \mathrm{mg} / \mathrm{kg} \\
\text { two weeks later } \\
\text { (single dose) }\end{array}$ & Obliterated & $\begin{array}{l}\text { Headaches down to } \\
\text { occasional (down from } \\
\text { severe) and improved } \\
\text { strength }(4+/ 5 \text { from } 4 / 5)\end{array}$ & $\begin{array}{l}\text { Improvement } \\
\text { of RIN } \\
\text { (decrease } \\
\text { in T2 FLAIR) }\end{array}$ \\
\hline $\begin{array}{l}\text { Preuss } \\
\text { et al. [13] }\end{array}$ & 9 yr male & $\begin{array}{l}5 \mathrm{mg} / \mathrm{kg} 4 \text { cycles } \\
\text { every } 2 \text { weeks }\end{array}$ & Obliterated & $\begin{array}{l}\text { Initial clinical improvement } \\
\text { but long-term overall } \\
\text { minimal improvement. } \\
\text { Identical manual ability } \\
\text { classification system } \\
\text { (MACS) pre-/posttreatment }\end{array}$ & $\begin{array}{l}\text { Cerebral edema } \\
\text { reduction } \\
\text { (via T2 FLAIR) }\end{array}$ \\
\hline $\begin{array}{l}\text { Preuss } \\
\text { et al. [13] }\end{array}$ & 9 yr female & $\begin{array}{l}5 \mathrm{mg} / \mathrm{kg} 4 \text { cycles } \\
\text { every } 2 \text { weeks } \\
\text { (+7 additional } \\
\text { cycles after } \\
\text { steroid cessation) }\end{array}$ & Obliterated & $\begin{array}{l}\text { Initial clinical improvement } \\
\text { but long-term overall } \\
\text { minimal improvement. } \\
\text { Identical MACS } \\
\text { pre-/posttreatment }\end{array}$ & $\begin{array}{l}\text { Cerebral edema } \\
\text { reduction } \\
\text { (via T2 FLAIR) }\end{array}$ \\
\hline $\begin{array}{l}\text { Dashti } \\
\text { et al. [14] }\end{array}$ & 12 yr female & $\begin{array}{l}2.5 \mathrm{mg} / \mathrm{kg} \\
\text { following } \\
\text { hyperosmotic } \\
\text { BBBD }\end{array}$ & $\mathrm{N} / \mathrm{A}$ & $\begin{array}{l}\text { Headache down to } 5 / 10 \\
\text { (from } 10 / 10 \text { severe), } \\
\text { strength improved to } \\
\text { walking with help of } \\
\text { electronic boot (from } \\
\text { 0/5 R hand/foot strength) }\end{array}$ & $\begin{array}{l}78 \% \text { decrease } \\
\text { in T2 FLAIR }\end{array}$ \\
\hline $\begin{array}{l}\text { Dashti } \\
\text { et al. [14] }\end{array}$ & $11 \mathrm{yr}$ female & $\begin{array}{l}2.5 \mathrm{mg} / \mathrm{kg} \\
\text { following } \\
\text { hyperosmotic } \\
\text { BBBD }\end{array}$ & $\mathrm{N} / \mathrm{A}$ & $\begin{array}{l}\text { Complete resolution of } \\
\text { headaches (from } \\
\text { intractable headaches } \\
+\mathrm{N} / \mathrm{V} \text { ) }\end{array}$ & $\begin{array}{l}74 \% \text { decrease } \\
\text { in T2 FLAIR }\end{array}$ \\
\hline $\begin{array}{l}\text { Turner } \\
\text { et al. [2] }\end{array}$ & 43 yr male & $\begin{array}{l}7.5 \mathrm{mg} / \mathrm{kg} \times \\
\text { tri-weekly }(\times 3 \mathrm{wk})\end{array}$ & Obliterated & $\begin{array}{l}\text { Completely resolution } \\
\text { of symptoms }\end{array}$ & $\begin{array}{l}\text { Full recovery } \\
\text { from RIN }\end{array}$ \\
\hline $\begin{array}{l}\text { Uysal } \\
\text { et al. [15] }\end{array}$ & 41 yr male & $\begin{array}{l}\text { Initial } 2.5 \mathrm{mg} / \mathrm{kg} \text {, } \\
\text { then }(2 \mathrm{wk} \text { later }) \\
7.5 \mathrm{mg} / \mathrm{kg} \text { every } \\
2 \text { weeks for } \\
4 \text { cycles }\end{array}$ & Obliterated & $\begin{array}{l}\text { Hemiparesis improved } \\
\text { to } 4 / 5 \text { (from } 2 / 5 \text { ), headache } \\
\text { improvement, and } \\
\text { ambulatory improvement }\end{array}$ & $\begin{array}{l}\text { Perilesional } \\
\text { edema } \\
\text { significantly } \\
\text { resolved (via } \\
\text { cranial CT) }\end{array}$ \\
\hline $\begin{array}{l}\text { Kwong } \\
\text { et al. } \\
{[2020]}\end{array}$ & 22 yr female & $\begin{array}{l}5 \mathrm{mg} / \mathrm{kg}, 2 \text { cycles } \\
2 \text { weeks apart }\end{array}$ & Obliterated & $\begin{array}{l}\text { Improvement in headache, } \\
\text { hypertonicity, and } \\
\text { ambulatory ability }\end{array}$ & $\begin{array}{l}\text { Mild decrease } \\
\text { in T2 FLAIR }\end{array}$ \\
\hline
\end{tabular}

AVM, arteriovenous malformations; RIN, radiation-induced necrosis; CT, computed tomography.

The results from Dashti et al. [14] showed reduction or resolution of severe headaches and over a 70\% reduction in T2 FLAIR in both the patients. Turner et al. [2] reported full recovery from steroid-refractory RIN post-SRS for AVM, including complete resolution of severe headaches and hemiparesis with bevacizumab. Uysal et al. [15] reported a patient with steroid-resistant RIN post-SRS for AVM who experienced improvement in headache, hemiparesis, and ambulation along with significant resolution of perilesional edema on computed tomography [15]. 


\section{Conclusion}

AVMs are extremely dangerous with previously ruptured malformations having as high as a $4-8 \%$ annual risk of hemorrhage. For inoperable lesions, SRS is a mainstay of treatment with variations in efficacy and technique based on the nidus size and SpetzlerMartin grade. Even SRS to a small AVM nidus can result in RIN. This risk is even higher in a previously irradiated region. Symptomatic management with steroids can be highly effective and is the mainstay of early management. For steroid treatment greater than 28 days in duration, the risks of adrenal insufficiency, myalgias, thermal dysregulation, and cerebrovascular accidents all increase significantly. Additionally, the poor control of radiation-induced necrosis can result in permanent neurologic dysfunction. After one month of steroid use, if not contraindicated, infusion of bevacizumab should be considered to manage RIN.

\section{Statement of Ethics}

The authors state that they have followed the principles outlined in the Declaration of Helsinki for all human experimental investigation. Written informed consent was obtained from the patient for publication of this case report and any accompanying images involved.

\section{Conflict of Interest Statement}

Dr. McClelland III reports grants from the Indianapolis Public Transportation Corporation; outside the submitted work. Dr. Barajas reports grants from K08 CA237809-01A1, outside the submitted work. Other authors have nothing to disclose.

\section{Funding Sources}

No funding was received.

\section{Author Contributions}

Conception and design: Jerry. J. Jaboin. Data collection: Jerry J. Jaboin and Forrest Kwong. Data analysis and interpretation: Ramon F. Barajas Jr., Debra Monaco, James A. Tanyi, and Jerry J. Jaboin. Manuscript writing: Forrest Kwong, Daphne B. Scarpelli, and Jerry J. Jaboin. The final approval of the manuscript: Forrest Kwong, Daphne B. Scarpelli, Ramon F. Barajas Jr., Debra Monaco, James A. Tanyi, Shearwood McClelland III, and Jerry J. Jaboin.

\section{References}

1 Blonigen BJ, Steinmetz RD, Levin L, Lamba MA, Warnick RE, Breneman JC. Irradiated volume as a predictor of brain radionecrosis after linear accelerator stereotactic radiosurgery. Int J Radiat Oncol Biol Phys. 2010 Jul 15;77(4):996-1001.

2 Turner RC, Lucke-Wold BP, Josiah D, Gonzalez J, Schmidt M, Tarabishy AR, et al. Stereotactic radiosurgery planning based on time-resolved CTA for arteriovenous malformation: a case report and review of the literature. Acta Neurochir. 2016 Aug;158(8):1555-62.

\section{Karger'}


3 Spetzler RF, Martin NA. A proposed grading system for arteriovenous malformations. J Neurosurg. 1986 Oct; 65(4):476-83.

4 Pollock BE, Link MJ, Stafford SL, Lanzino G, Garces YI, Foote RL. Volume-staged stereotactic radiosurgery for intracranial arteriovenous malformations: outcomes based on an 18-year experience. Neurosurgery. 2017 Apr 1;80(4):543-50.

5 Yen CP, Schlesinger D, Sheehan JP. Natural history of cerebral arteriovenous malformations and the risk of hemorrhage after radiosurgery. Prog Neurol Surg. 2013;27:5-21.

6 Potts MB, Sheth SA, Louie J, Smyth MD, Sneed PK, McDermott MW, et al. Stereotactic radiosurgery at a low marginal dose for the treatment of pediatric arteriovenous malformations: obliteration, complications, and functional outcomes. J Neurosurg Pediatr. 2014 Jul;14(1):1-11.

7 Miyawaki L, Dowd C, Wara W, Goldsmith B, Albright N, Gutin P, et al. Five year results of LINAC radiosurgery for arteriovenous malformations: outcome for large AVMS. Int J Radiat Oncol Biol Phys. 1999 Jul 15;44(5): 1089-106.

8 Levin VA, Bidaut L, Hou P, Kumar AJ, Wefel JS, Bekele BN, et al. Randomized double-blind placebo-controlled trial of bevacizumab therapy for radiation necrosis of the central nervous system. Int J Radiat Oncol Biol Phys. 2011 Apr 1;79(5):1487-95.

9 Randall LM, Monk BJ. Bevacizumab toxicities and their management in ovarian cancer. Gynecol Oncol. 2010 Jun;117(3):497-504.

10 Gressett SM, Shah SR. Intricacies of bevacizumab-induced toxicities and their management. Ann Pharmacother. 2009 Mar;43(3):490-501.

11 Yang L, Chen CJ, Guo XL, Wu XC, Lv BJ, Wang HL, et al. Bevacizumab and risk of intracranial hemorrhage in patients with brain metastases: a meta-analysis. J Neurooncol. 2018 Mar;137(1):49-56.

12 Williams BJ, Park DM, Sheehan JP. Bevacizumab used for the treatment of severe, refractory perilesional edema due to an arteriovenous malformation treated with stereotactic radiosurgery. J Neurosurg. 2012 May; 116(5):972-7.

13 Preuss M, Hirsch W, Hoffmann KT, Bernhard MK, Siekmeyer M, Kiess W, et al. Effectiveness of bevacizumab for radiation-induced cerebral necrosis in children. Pediatr Neurosurg. 2013;49(2):81-5.

14 Dashti SR, Spalding A, Kadner RJ, Yao T, Kumar A, Sun DA, et al. Targeted intraarterial anti-VEGF therapy for medically refractory radiation necrosis in the brain. J Neurosurg Pediatr. 2015 Jan;15(1):20-5.

15 Uysal E, Baskurt O, Avci I, Peker HO, Celik SE. Late recovery of stereotactic radiosurgery induced perilesional edema of an arteriovenous malformation after bevacizumab treatment. Br J Neurosurg. 2020 Mar 27;1-5. 